\title{
Self-Developable Surface Relief Photoimaging Generated by Anionic UV-Curing of Epoxy Resins
}

\author{
By Ken'ichi AOKI ${ }^{1,2, *}$ and Kunihiro ICHIMURA ${ }^{1,2}$
}

The self-developable formation of photoinduced surface relief was achieved by the post-exposure baking (PEB) of patternwise UV-exposed films consisting of a photobase generator, a branched base amplifier and an epoxy resin. A photogenerated amine triggered the self-catalytic fragmentation of a branched base amplifier to give branched molecules substituted with $\omega$ amino groups, which reacted with an epoxy resin during PEB to form crosslinked networks. The consumption of ingredients as a result of the fragmentation and the crosslinking reactions during PEB generates the concentration gradients of components, leading to the mass transfer from unexposed areas to exposed ones to give surface relief structures.

KEY WORDS: Photobase Generation / Base-Proliferation Reaction / Epoxy Resin / Mass Transfer / Surface Relief /

Photoinduced surface relief have been attracting ever increasing interest from both fundamental and practical views. ${ }^{1}$ Materials inscribing surface relief structures induced by holographic or pattern-wise exposure include predominantly polymeric and oligomeric films substituted with azobenzene side chains exhibiting reversible photoisomerization, during which the mass transfer occurs. Whereas photoisomerizable chromophores other than azobenzene including styrylpyridinium, ${ }^{2}$ cinnamate, ${ }^{3}$ spiropyran $^{4}$ and diarylethene ${ }^{5}$ have been covalently attached to or physically mixed with polymers to demonstrate surface relief formation, the mechanism for the mass transfer induced solely by photoirradiation has still been controversial. The other approach leading to the photoinduced mass transfer is based on the radical photopolymerization of acrylates to perform self-developable imaging. The image-wise exposure of a free-standing film of an acrylate containing a photoinitiator results in the movement of acrylate molecules from unexposed areas to exposed ones. ${ }^{6}$ This technique was applied to fabricate microarray lenses. ${ }^{7}$ In order to optimize the materials for practical applications, the self-developable radical photopolymerization was achieved by formulating acrylate monomers with binder polymers to give tack-free films. ${ }^{8,9}$

During our photosensitivity determination of anionically UV-curable materials comprised of a photobase generator, a base-amplifier and an epoxy resin, ${ }^{10}$ we incidentally observed that relief images are formed during post-exposure baking
(PEB). ${ }^{11}$ The chemistry for the imaging of our materials involves the photogeneration of an amine as a basic catalyst, the autocatalytic deprotection of 9-fluorenylmethoxycarbonyl (Fmoc) units of a base-amplifier (Scheme 1) ${ }^{12}$ and the addition of amino groups thus formed to epoxy residues. While the former is a photochemical event, the latter two belongs to thermal chemistry so that the self-developable imaging is essentially influenced by post-exposure baking. We report here that the mass transfer of ingredients for anionic UV-curing enhanced by a base-amplifying oligomer takes place from unexposed to exposed areas of thin films and is affected by factors including the nature of epoxy resins, exposure time, post-exposure time and temperature.

\section{EXPERIMENTAL}

\section{Materials}

The materials used here are shown in Scheme 2. The base amplifier $(\mathbf{1})^{10}$ and the photobase generator $(\mathbf{2})^{13}$ were synthesized according to the literatures. 2-Isocyanatoethyl acrylate was gifted by Showa Denko Co., whereas 9-fluorenylmethanol was purchased from Tokyo Kasei. Epoxylated Novolac resin (3) with $M_{\mathrm{w}}=2100$ and $M_{\mathrm{w}} / M_{\mathrm{n}}=1.60$ and a multi-functional epoxy compound (4) were kindly gifted by Tohto Chemical Co. and Nagase Chemtex Co., respectively. Note that the chemical structures of $\mathbf{3}$ and $\mathbf{5}$ are tentatively

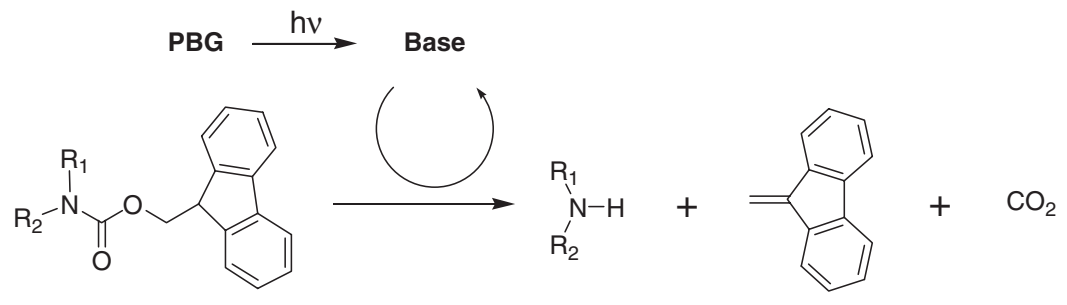

Scheme 1. The concept of the base-proliferation.

\footnotetext{
${ }^{1}$ Faculty of Science, Toho University, 2-2-1 Miyama, Funabashi 274-8510, Japan

${ }^{2}$ Research Center for Materials with Integrated Properties, Toho University, 2-2-1 Miyama, Funabashi 274-8510, Japan

*To whom correspondence should be addressed (Tel: +81-47-472-1331, Fax: +81-47-472-1331, E-mail: k-aoki@ sci.toho-u.ac.jp).
} 
<smiles>CC(C)OC(=O)CSCCC(=O)OCCNC(=O)OCC1c2ccccc2-c2ccccc21</smiles>

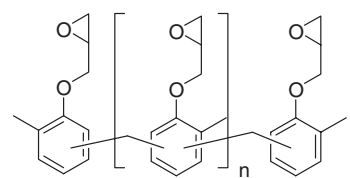<smiles>COc1cc(COC(=O)N2CCC(CCCCC3CCN(C(=O)OCc4cc(OC)c(OC)cc4[N+](=O)[O-])CC3)CC2)c([N+](=O)[O-])cc1OC</smiles>

2

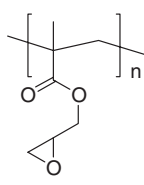

5

Scheme 2. Chemical structures of the compounds used in this study.

illustrated according to commercial catalogues whereas they were complicated mixtures. Poly(glycidyl methacrylate) (5) with $M_{\mathrm{w}}=1.3 \times 10^{4}$ and $M_{\mathrm{w}} / M_{\mathrm{n}}=2.40$ was prepared by the radical polymerization initiated by azobisisobutyronitrile.

\section{Self-Developable Photopatterning}

A mixture of $\mathbf{1 , 2}$ and an epoxy compound $(\mathbf{3}, \mathbf{4}$, or $\mathbf{5})$ was dissolved in a $1: 1(\mathrm{v} / \mathrm{v})$ mixed solvent of propyleneglycol methylether acetate (PGMEA) and chloroform, and the solution was spin-cast on a glass substrate at $1000 \mathrm{rpm}$ for $30 \mathrm{~s}$ to give a film, which was pre-baked at $100^{\circ} \mathrm{C}$ for $1 \mathrm{~min}$. The photoirradiation of the film was carried out using a San-ei Supercure-203S Hg-Xe lamp passed through a combination of glass filters to select $365 \mathrm{~nm}$ light and a photomask having periodical lines and spaces (L\&S). After the subsequent heating at $130{ }^{\circ} \mathrm{C}$ for $20 \mathrm{~min}$, surface textures of films were evaluated by using an optical microscope (ECLIPSE/ME600, Nikon) and a surface profiler (KLA Tencor, Alpha-Step IQ). FT/IR spectra of films were recorded on a FT/IR-300E (JASCO) spectrophotometer.

\section{RESULTS AND DISCUSSION}

The four-armed base-amplifier $(\mathbf{1})^{10}$ was prepared by the
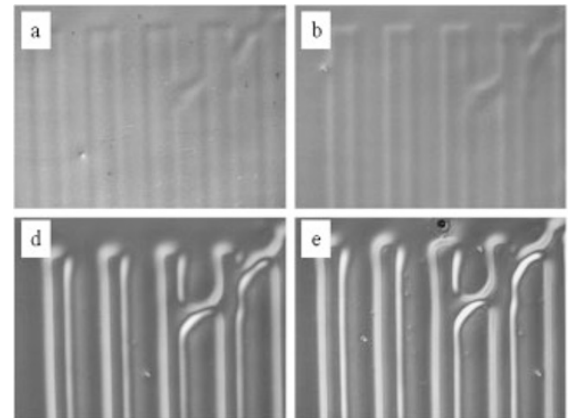

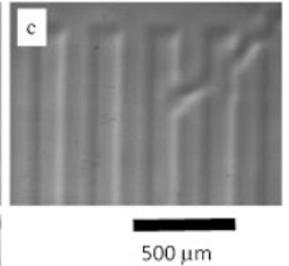

$500 \mu \mathrm{m}$
Figure 1. Differential interference contrast optical micrographs of a film of $1.17 \mu \mathrm{m}$-thickness exposed to $365 \mathrm{~nm}$ light of a $450 \mathrm{~mJ} / \mathrm{cm}^{2}$ dose through a photomask with $100 \mu \mathrm{m}$ L\&S, followed by baking at $130^{\circ} \mathrm{C}$ for (a) $5 \mathrm{~min}$, (b) $7 \mathrm{~min}$, (c) $10 \mathrm{~min}$, (d) $15 \mathrm{~min}$ and (e) $20 \mathrm{~min}$.
Michael addition of the corresponding tetrathiol and 9fluorenylmethyl $\mathrm{N}$-(2-acryloxyethyl)carbamate, which was synthesized in advance by the reaction of commercially available 2-isocyanatoethyl acrylate and 9-fluorenylmethanol. ${ }^{14} \mathrm{We}$ observed previously that efficiencies for the photoinsolubilization of compositions comprised of 1, 2 and 3 or 4 are markedly dependent on post-exposure baking (PEB) conditions, suggesting that the mobility of a deprotected polyamine derived from $\mathbf{1}$ determines the photosensitivity performances. ${ }^{10}$ It was also recognized that images become visible without wet development when a film of a mixture of $\mathbf{1}$, 2 and $\mathbf{3}$ is exposed to $365 \mathrm{~nm}$ light through a photomask, followed by $\mathrm{PEB}$ at $130{ }^{\circ} \mathrm{C}$. The observation indicated that the film is self-developable and consequently motivated us to study surface textures of films in detail. Photosensitive materials were formulated by dissolving a ternary mixture of $\mathbf{1 , 2}$ and $\mathbf{3}$ in 4.5:1:10 by weight in a 1:1 (v/v) mixure of PGMEA and chloroform to give a tack-free film by spin coating. The weight ratio of $\mathbf{1}$ and $\mathbf{3}$ was optimized to give reasonable photosensitivity. The films were exposed to $365 \mathrm{~nm}$ light of a dose of $450 \mathrm{~mJ} / \mathrm{cm}^{2}$ through a photomask and subjected to PEB. The PEB was performed at $130{ }^{\circ} \mathrm{C}$, since 1 suffered from the

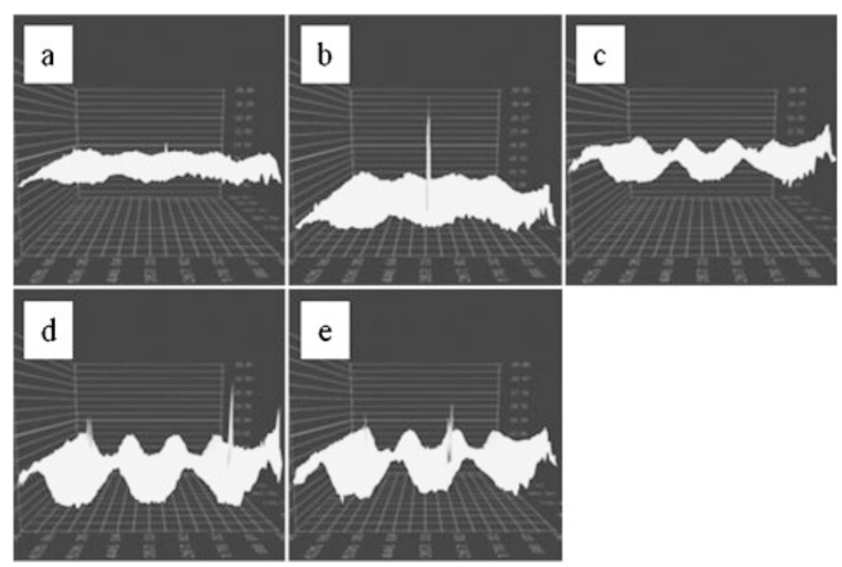

Figure 2. The surface structures of films taken by means of a laser scanning microgscope. The films are arranged in the same order as presented in Figure 1. 
(A)

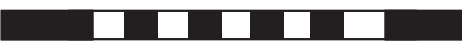

(a)

(b)

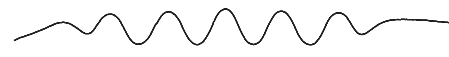

(c)
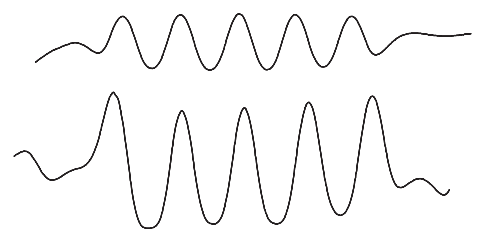

(d)

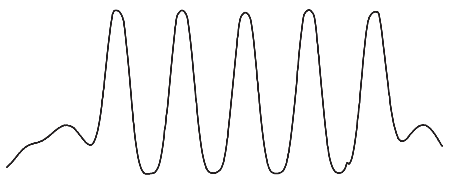

(e)

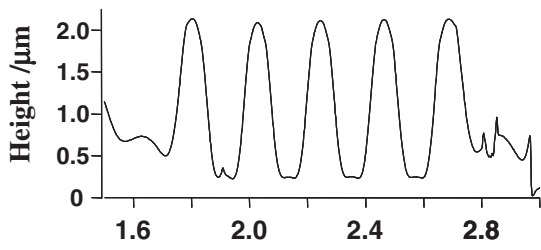

Horizonal length / mm
(B)

(a)

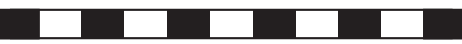

(b)

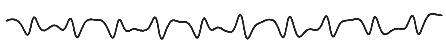

(c)

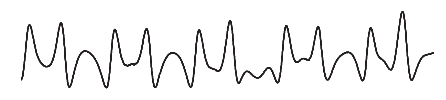

(d)

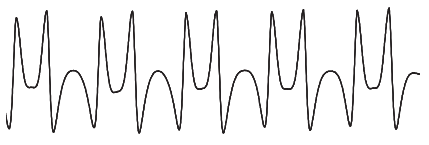

(e)

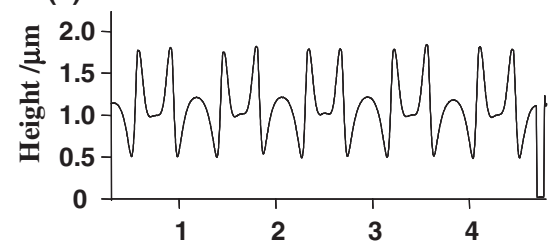

Horizonal length / mm

Figure 3. Surface profiles of films of $1.17 \mu \mathrm{m}$ thickness exposed to $365 \mathrm{~nm}$ light through a photomask of (A) L\&S $=100 \mu \mathrm{m}$ and (B) $\mathrm{L \& S}=500 \mu \mathrm{m}$, followed by baking at $130^{\circ} \mathrm{C}$ for (a) $5 \mathrm{~min}$, (b) $7 \mathrm{~min}$, (c) $10 \mathrm{~min}$, (d) $15 \mathrm{~min}$ and (e) $20 \mathrm{~min}$.

thermal decomposition at a higher temperature of $150{ }^{\circ} \mathrm{C}$, whereas PEB at temperatures below $100^{\circ} \mathrm{C}$ caused reluctant cross-linking reaction. Figure 1 shows optical micrographs of the films after PEB under a differential interference contrast (DIC) mode. Photoimages were generated faintly upon PEB for 5 min, followed by enhancing the images upon further PEB and became clear after the PEB for longer than $10 \mathrm{~min}$. Figure 2 shows the three-dimesional photoimages recorded by means of a laser scanning microscope to confirm the formation of inscribed patterns with smooth surfaces. Surface profiles of inscribed images were thus recorded to reveal that the profiles were influenced not only by PEB time, but also by loading amounts of 3, lines and spaces (L\&S) of a mask and film thickness, as described below.

The profile patterns formed on a film of $1.17 \mu \mathrm{m}$ thickness were recorded on a profilometer as a function of PEB period to obtain two experimental sequences after the photoirradiation through a photomask of L\&S of $100 \mu \mathrm{m}$ (Figure 3(A)) and of $500 \mu \mathrm{m}$ (Figure $3(\mathrm{~B})$ ). The results gave us versatile information. Firstly, the thickness of unexposed areas is markedly reduced, whereas exposed areas become thicker as a result of the mass transfer from unexposed areas to exposed ones, as clearly seen in Figure 3(A). This indicates unequivocally that the consumption of component molecules at the exposed areas generates a concentration gradient, which works as a driving force to lead to the migration of molecules. Secondly, the amplitude of the surface relief grew as a function of PEB time. In order to visualize the growth of the relief structure, a difference $(\Delta D)$ between a peak height and a valley depth was plotted as a function of PEB period, as given in Figure 4. The values $\Delta \mathrm{D}$ increase abruptly at $7 \mathrm{~min}$ baking and almost leveled off at $15 \mathrm{~min}$ heating. In order to elucidate the thermal event during $\mathrm{PEB}$, changes in absorbance of $v_{\mathrm{C}=\mathrm{O}}$ at $1730 \mathrm{~cm}^{-1}$ in FT/IR-spectra of a film consisting of $\mathbf{1}, \mathbf{2}$ and $\mathbf{3}$ were recorded, whereas the $v_{\mathrm{C}=\mathrm{O}}$ band is not only due to the urethane linkage, but also due to ester bonds of 2 . The decrease in band intensity was leveled off at 5 min-heating because of the termination of the deprotection, indicating that the inscription grows just after the deprotection. Accordingly, oligomer molecules substituted with $\omega$-amino groups migrate thereafter, probably competing with the reaction with 3 . As revealed by the results shown in Figure 3(A), the thickness of exposed areas of the film of $1.17 \mu \mathrm{m}$ is considerably reduced down to about $0.2 \mu \mathrm{m}$ or less after PEB. The driving force is the

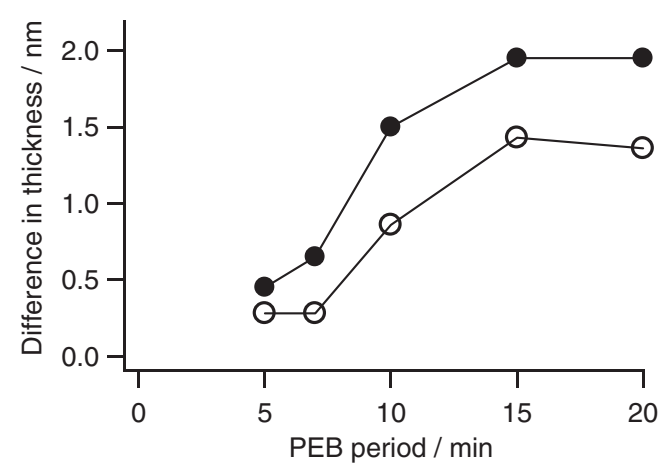

Figure 4. Difference in thickness at peaks and volleys of a film of 1, 2 and 3 exposed to $365 \mathrm{~nm}$ light through a photomask of L\&S $=100 \mu \mathrm{m}$ (open circles) and (b) of $\mathrm{L} \& S=500 \mu \mathrm{m}$ (closed circles) as a function of PEB period. 
(a)

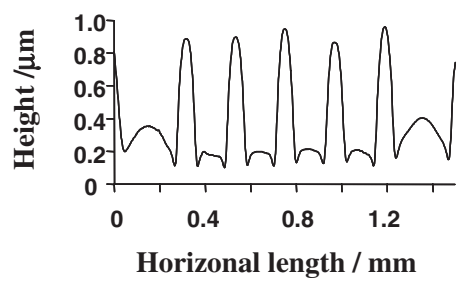

(b)

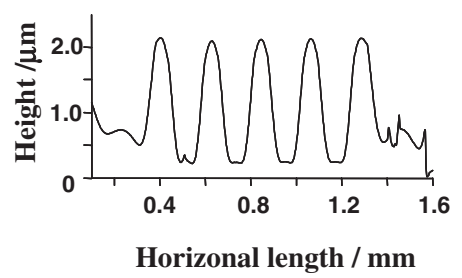

(c)

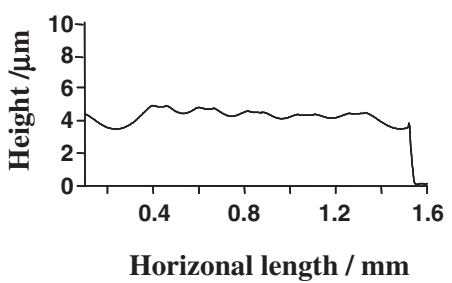

Figure 5. Dependence of thickness of profile shapes of films of a mixture (4.5:1:10 in weight) of 1, 2 and $\mathbf{3}$ exposed to $365 \mathrm{~nm}$ light through a photomask of $\mathrm{L} \& \mathrm{~S}=100 \mu \mathrm{m}$, followed by heating at $130^{\circ} \mathrm{C}$ for $20 \mathrm{~min}$. Film thickness: (a); $0.370 \mu \mathrm{m},(\mathrm{b}) ; 1.17 \mu \mathrm{m},(\mathrm{c}) ; 4.38 \mu \mathrm{m}$.

concentration gradient of the ingredients, which is caused by the reaction of $\mathbf{3}$ with the deprotected oligomer molecules. Thirdly, the profile shape is influenced considerably by L\&S. When L\&S was $500 \mu \mathrm{m}$, the profile was complicated, as seen in Figure 3(B), when compared with that for $L \& S$ of $100 \mu \mathrm{m}$. The peculiar shape under $500 \mu \mathrm{m}-\mathrm{L} \& \mathrm{~S}$ is interpreted reasonably in terms of the displacement length of component molecules. The distance between peaks at edges of exposed areas and the corresponding nearest valleys at the edges of unexposed areas is $c a .100 \mu \mathrm{m}$, revealing that this value is equivalent to the length of the maximum mass migration. Consequently, the mass migration from the central part of unexposed areas having a $500 \mu \mathrm{m}$ width occurs hardly to form the characteristic line shape with symmetry. In the case of $100 \mu \mathrm{m}-\mathrm{L} \& \mathrm{~S}$, on the other hand, molecules in unexposed areas can be transferred efficiently to exposed areas.

The dependence of film thickness is illustrated in Figure 5. Whereas the distinct inscription was generated under $100 \mu \mathrm{m}$ L\&S for a thinner film of $0.37 \mu \mathrm{m}$ in a manner similar to that of $1.17 \mu \mathrm{m}$ thickness, no clear profile was obtained for a thicker film of $4.38 \mu \mathrm{m}$. This is believed to come from the incomplete photolysis of $\mathbf{2}$ in deeper sites of a film because of the light absorption at surface regions of a film to result in the insufficient and inhomogeneous generation of a photogenerated base. Consequently, among the films tested, the most favorable thickness is $1.17 \mu \mathrm{m}$.

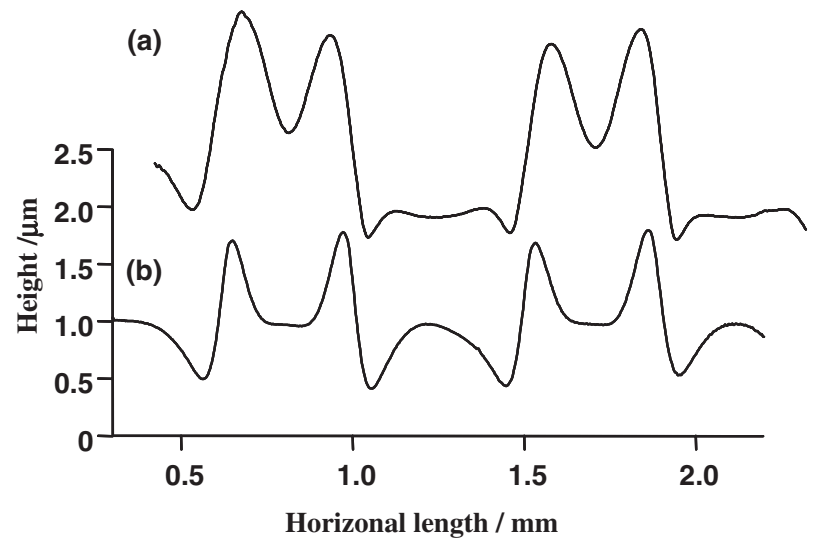

Figure 6. Profiles shapes of films of (a) 1, 2 and 3 and of (b) 1, 2 and 5 exposed to $365 \mathrm{~nm}$ light through a photomask of $500 \mu \mathrm{m}$ L\&S, followed by baking at $130^{\circ} \mathrm{C}$ for $20 \mathrm{~min}$.
In order to confirm that the performance of the inscription is influenced by the mobility of epoxy resins, a fluid multi-epoxy compound (4) and an epoxy polymer (5) as a solid were employed for the photosensitive formulation. It was found that the polymer 5 gives no surface relief structure, implying that polymer chains are not movable due to a large molecular size and crosslinking during PEB. On the other hand, a film containing 4 exhibited longer diffusion length, when compared with that of 3, as shown in Figure 6. The film thickness is markedly reduced in the whole unexposed areas of $0.5 \mathrm{~mm}$ width, disclosing that molecules travel at a distance longer that ca. $0.25 \mathrm{~mm}$. It is anticipated the thickness in the middle of exposed areas is not increased even for the film containing $\mathbf{3}$ because the diffusion of molecules is suppressed by the crosslinked networks.

\section{CONCLUSION}

A film consisting of a photobase generator, a base amplifier and an epoxy resin generates self-developable surface relief after UV-exposure and the subsequent PEB processes. Profile shapes of the surface images were influenced critically by film thickness, lines and shapes of a photomask and the nature of epoxy compounds. Epoxylated Novolac resin and fluid multifunctional epoxy resin were suitable components for formulating photosensitive materials, whereas film thickness of thinner than $c a .1 .2 \mu \mathrm{m}$ gave satisfactory results for the surface relief formation. A mixture of $\mathbf{1}, \mathbf{2}$ and $\mathbf{3}$ is convenient for the selfdevelopable surface imaging for practical application, because a tack-free film suffers from no inhibitory effect of the UVcuring by atmosphoric oxygen so that the relief structure is modulated by PEB conditions.

Acknowledgment. The authors are obliged to Industrial Technology Research Grant Program (No. 04A25522d) from New Energy and Industrial Technology Development Organization (NEDO) of Japan (K. A.) and to Sekisui Chemical Co., Ltd. (K. I.) for the financial supports and to Dr. Hiroji Fukui and Mr. Hiroshi Kobayashi at Sekisui chemical Co., Ltd. for the laser scanning microscope measurements.

Received: July 7, 2009

Accepted: July 24, 2009

Published: September 10, 2009 


\section{REFERENCES}

1. a) K. G. Yager and C. J. Barrett, Curr. Opin. Solid State Mater. Sci., 5, 487 (2001).

b) A. Natansohn and P. Rochon, Chem. Rev., 102, 4139 (2002).

c) N. K. Viswanathan, D. Y. Kim, S. Bian, J. Williams, W. Liu, L. Li, L. Samuelson, J. Kumarab, and S. K. Tripathy, J. Mater. Chem., 9, 1941 (1999).

d) T. Seki, Curr. Opin. Solid State Mater. Sci., 10, 241 (2006).

e) O. N. Oliveira, D. S. dos Santos, D. T. Balogh, V. Zucolotto, and C. R. Mendonca, Adv. Collid Interface Sci., 116, 179 (2005).

2. S. Yamaki, M. Nakagawa, S. Morino, and K. Ichimura, Appl. Phys. Lett., 76, 2520 (2000).

3. N. Kawatsuki, T. Hasegawa, H. Ono, and T. Tamoto, Adv. Mater., 15, 991 (2003).

4. T. Ubukata, K. Takahashi, and Y. Yokoyama, J. Phys. Org. Chem., 20, 981 (2007).

5. T. Ubukata, S. Yamaguchi, and Y. Yokoyama, Chem. Lett., 36, 1224 (2007).

6. a) L. Lavielle, C. Croutxé-Barghorn, E. Schuller, and D.-J. Lougnot, J. Colloid Interface Sci., 192, 149 (1997).

b) C. Croutxé-Barghorn and D. J. Lougnot, Pure Appl. Opt., 5, 811 (1996).

c) L. Lavielle, C. Croutxé-Barghorn, E. Schuller, and D.-J. Lougnot, J. Photochem. Photobiol., A, 104, 213 (1997).

d) S. Calixto, C. Croutxé-Barghorn, and D. J. Lougnot, Eur. Phys. J. Appl. Phys., 8, 29 (1999).

e) C. Croutxé-Barghorn, O. Soppera, and D. J. Lougnot, Appl. Surf. Sci., 168, 89 (2000).

f) C. Croutxé-Barghorn, O. Soppera, and D. J. Lougnot, Eur. Phys. J. Appl. Phys., 13, 31 (2001).
7. a) O. Soppera, C. Croutxé-Barghorn, C. Carré, and D. Blanc, Appl. Surf. Sci., 186, 91 (2002).

b) D. Blanc, S. Pélissier, P. Y. Jurine, O. Soppera, C. CroutxéBarghorn, and C. Carré, J. Sol-Gel Sci. Technol., 27, 215 (2003).

c) C. Croutxé-Barghorn, O. Soppera, and M. Chevallier, Macromol. Mater. Eng., 288, 219 (2003).

8. C. Sánchez, B.-J. de Gans, D. Kozodaev, A. Alexev, M. J. Escuti, C. van Heesch, T. Bel, U. S. Shubert, C. W. M. Bastiaansen, and D. J. Broer, Adv. Mater., 17, 2567 (2005).

9. K. Hermans, F. K. Wolf, J. Perelaer, R. A. J. Janssen, U. S. Schubert, C. W. M. Bastiaansen, and D. J. Broer, Appl. Phys. Lett., 91, 174103 (2007).

10. a) K. Aoki, K. Arimitsu, and K. Ichimura, J. Photopolym. Sci. Technol., 18, 133 (2005).

b) K. Aoki and K. Ichimura, J. Photopolym. Sci. Technol., 19, 683 (2006).

c) K. Aoki and K. Ichimura, Macromol. Chem. Phys., 210, 1303 (2009).

11. K. Aoki and K. Ichimura, J. Photopolym. Sci. Technol., 19, 49 (2006).

12. a) K. Arimitsu, M. Miyamoto, and K. Ichimura, Angew. Chem., Int. Ed., 39, 3425 (2000).

b) K. Ichimura, Chem. Rec., 2, 46 (2002).

c) K. Arimitsu and K. Ichimura, J. Mater. Chem., 14, 336 (2004).

13. E. J. Urankar, I. Brehm, Q. J. Niu, and J. M. J. Fréchet, Macromolecules, 30, 1304 (1997).

14. a) K. Ichimura, A. Igarashi, K. Arimitsu, and T. Seki, J. Photopolym. Sci. Technol., 17, 433 (2004).

b) A. Igarashi, K. Arimitsu, K. Aoki, and K. Ichimura, J. Photopolym. Sci. Technol., 18, 419 (2005).

c) A. Igarashi, K. Arimitsu, T. Seki, and K. Ichimura, J. Mater. Chem., 18, 560 (2008). 